\title{
Perspective of Teachers on the Cross-Curricular Pedagogical Approach for Children With Developmental Disabilities
}

\author{
Shaina Mary Paul 1 and Naveen Singh $\mathbb{B}$
}

The National Education Policy 2020 has voiced its interest and need for an evolved pedagogy attuned to the importance of quality education for all. The policy stresses the importance of one such creative pedagogical approach called the cross-curricular pedagogical approach. This study aims to assess the level of awareness and perspective of primary teachers, on the cross-curricular approach for children with developmental disabilities. The sample includes 100 teachers $(50$ general teachers and 50 special educators) in inclusive schools of Delhi-NCR. The data was collected using the survey method. Results indicate that $56 \%$ of general teachers and $80 \%$ of special educators are aware of the term 'cross-curricular pedagogical approach. However, only $22 \%$ of general teachers and $34 \%$ of special educators have attended workshops and training sessions on cross-curricular pedagogical approaches. Many of the general teachers and special educators expressed a positive perception towards forging linkages between subject disciplines for teaching children with developmental disabilities in inclusive classrooms.

KEYWORDS: National Education Policy 2020, Sports Integration, Children with Developmental Disabilities, Cross-Curricular Pedagogical Approach

\section{INTRODUCTION}

A close examination of the term 'Pedagogy' has revealed it to be unique and interactive in the recent times. The term has been redefined as an art following from the view that it refers to the "interactions between teachers, students, and

Shaina Mary Paul $₫$

Amity Institute of Rehabilitation Sciences, Amity University, Noida, India.

Email: shaina.paul9@gmail.com. ORCID: https://orcid.org/0000-0003-3879-4945

Naveen Singh

Amity Institute of Rehabilitation Sciences, Amity University, Noida, India.

Email: naveen_nimh@yahoo.co.in. ORCID: https://orcid.org/0000-0001-9657-1817 
the learning environment and learning tasks" Murphy (2008). It is the pedagogical approach adopted in the classroom that defines the learning experience and outcome.

Recognising the gap between the current state of learning outcomes and what is desired, India drafted a new education policy for undertaking major reforms in the education sector. The National Education Policy 2020 centred its focus vastly on how children learn and on the importance of an evolving pedagogy catering a holistic learning experience for all students; for it is an effective pedagogical approach that increases student's engagement, confidence and motivation in the classroom but also instils their interest in the process of learning.

Cross-Curricular Pedagogical Approach is one such creative approach in teaching and learning that suggests being "highly motivating, inclusive and able to raise standards in all subjects" Barnes (2015). Working definition of cross-curricular teaching as defined in CROSSCUT is a "teaching that involves a conscious effort to apply knowledge, skills, and competencies to more than one subject area simultaneously" (Timmerman, 2017).

Barnes (2015) in his chapter has classified the approach further into six types based on their aims, strategies, and learning outcomes - whether it is related to promoting interest and learning in one subject using another subject; furthering skills, knowledge and vocabulary in two subject disciplines through one single experience; "connect or combine" learnings of two subject disciplines creatively to create a new product, idea or presentation and so on.

The choice over the type of cross-curricular approach is up to a teacher noting the needs of the children and the learning that the teacher wishes to promote among them. It is important to note how all approaches can be used with all subject disciplines. Cross-curricular objectives can also be achieved at different stages of learning as mentioned by Palmer (1991). Lessons could be formulated with cross-curricular activities, developing cross-curricular sub objectives within a curriculum guide or by incorporating assessment activities that are cross-curricular in nature.

Forging connections between subject disciplines is a creative process of teaching and learning which particularly if we consider children with special needs respond quickly and positively to, when having their creativeness recognised and affirmed. Facts on how human brain functions and organises information effectively through holistic experiences also favours the cross curricular approach to make patterns across subject areas. Apart from motivating children, it provides an engaging new perspective for teachers as well. It promotes a personal sense of satisfaction and appraisal of creativity amongst teachers. However, success on the part of this approach is sustained through 
the active involvement of teachers throughout. Factors such as teacher's attitude, approach play their part in making the cross-curricular teaching and learning effective. It also notes down a practical advantage for teachers for either implementing it individually or collectively.

However, research conducted by Barnes (2015) mentions how crosscurricular approaches can sometimes sacrifice progression of skills, knowledge, understanding etc., in the subject for the sake of promoting enjoyment. We also take note of two key problems observed by Jacobs (1989) in his chapter "The Growing Need for Interdisciplinary Curriculum Content" that often plagues this approach:

1. The Potpourri Problem: The fact that the interdisciplinary approach has no general structure of its own, many units become samples of knowledge from each discipline and becomes difficult for framing a coherent view on the topic.

2. The Polarity Problem: Interdisciplinary and Discipline-field approaches have been poles apart causing various conflicts. Many teachers become highly territorial regarding their subjects and feel threatened by new views on their subjects.

This research study specifically pertains to children with developmental disabilities. Developmental Disabilities refers to various limitations in functions resulting from the disorders of the developing nervous system. These limitations occur in various functional domains such as cognition, motor performance, vision, hearing, speech and behaviour manifested during infancy or childhood due to the delays in reaching developmental milestones.

As defined in the Rights of Persons with Disabilities (RPWD) Act, 2016:

Intellectual disability is a condition characterised by significant limitation both in intellectual functioning (reasoning, learning, problem solving) and in adaptive behaviour which covers a range of everyday social and practical skills, including: -

a. Specific Learning Disabilities: which means a heterogeneous group of conditions wherein there is a deficit in processing language, spoken or written, that may manifest itself as a difficulty to comprehend, speak, read, write, spell or to do mathematical calculations and includes such conditions as perceptual disabilities, dyslexia, dysgraphia, dyscalculia, dyspraxia, and developmental aphasia;

b. Autism Spectrum Disorder: which means a neuro-developmental condition typically appearing in the first three years of life that significantly affects a person's ability to communicate, understand relationships and relate to others, and is frequently associated with unusual or stereotypical rituals or 
behaviour. (pp. 34)

\section{Review Of Related Literature}

jan-erik Romar, Bjorkgren, Snellman, Ruostekoski, and Juslenius (2020) in their study, gathered 28 female and 16 male Finnish Pre-Service Subject Teacher's perspectives and experiences with Movement Integration, i.e., use of physical activity or movement in the academic classroom. Data was collected through 8 focus group discussions, 4 formal semi-structured interviews, 1 audio taped workshop and through classroom observations and informal discussions. Data was analysed through Inductive Thematic Analysis Approach. The findings stated that movement integration was a new concept for the preservice teachers, and it positively influenced their beliefs regarding the usage of movement integration in academic lessons. The research also reported various benefits of the Movement Integration on students, such as increase in the students' work productivity and quality during the lesson. Pre-Service Subject Teachers also mentioned how easily Movement Integration could be integrated into secondary academic classrooms.

Timmerman (2017) in her publication highlights the key points of the discussion conducted about Cross-Curricular Teaching at a European Dissemination event based on the situational survey about Interdisciplinary Approach which took place in 5 European Countries under a project named CROSSCUT. The situational survey was conducted for noting the current status of Cross-Curricular Teaching in European Countries. In this particular survey, 23 schools were visited, observations of 31 teaching sessions, interviews of 26 school leaders and focus group interviews with 119 teachers were conducted at each school. Examples suggesting convergence of various disciplines of study of lower and upper secondary education were mentioned. The publication notes various arguments in favour of Cross-Curricular Teaching such as how objects, concepts, and events can be studied from different angles. It also recognises it as a tool to help the weakest pupils to gain knowledge. It notes down its practical advantage for teachers for either implementing it individually or collectively. It mentions various requirements for its implementation such as understanding about the approach and its potentiality, concrete examples and a broad mindset on the part of the teachers. Another objective of the survey was also to identify the enablers and obstacles of Cross-Curricular Teaching. The enablers were collaboration skills, teamwork, mutual understanding, and experience while the obstacles mentioned were teacher's attitude and capabilities, paucity of time and other practical issues.

Lynch (2016) in her article touches upon the concept of Cross-Curricular Integration by exploring the use of physical education for teaching literacy 
and math skills. Physical education and sports are said to have various naturally occurring opportunities for integrating math learning and to also develop written and verbal literacy. It may seem like a daunting task to implement cross-curricular strategies, but she says that it becomes easier when the tasks are introduced one at a time. Cross-Curricular Learning is also said to help students build cognitive bridges between information across varied disciplines and may also increase retention. The author provides various suggestive activities for implementing a Cross-Curricular Learning between various sports units and math and literacy. For instance, while playing soccer, the author suggests letting students count the successful goals for improving their counting skills.

Greenwood (2013) in his research mentions that the revised Northern Ireland Primary Curriculum staunchly promotes Cross-Curricular Approach to planning and teaching and specially considers the Cross-Curricular link between geography alongside history and science and technology in its structure. The study analysed the opinions of the Teachers collected through questionnaires and interviews, which was mostly positive regarding the effectiveness of this approach in improving pupil learning and for providing a more holistic, relevant, and meaningful learning experience for them. One of the most frequently made comment in the study noticed was also the fact that the combination of history, science and geography was a natural, meaningful and a relevant one.

Thomson, Hall, and Jones (2012) explored the implications of CrossCurricular Approach undertaken by English Schools in association with Creative Partnerships, a national program funded to work with teachers to make schools more lively, engaging, and imaginative. Cross-Curricular Approach as mentioned in the report is a generic term to indicate a move away from strict subject-based teaching. The research employed qualitative methods like interviews, field observations, document analysis to observe patterns of change imposed by the approach. As observed particularly in the primary level, the teachers believed that the children learnt better if the subject disciplines were linked. History, English, Art, or Science, Art, English and Geography were noted as common combinations. Teachers also equated fun with engagement and meaningful learning. The study also observed a lack of familiarity with historical experiences and international literatures related to cross-curriculum work.

Based on the literature review, it was found that the cross-curricular pedagogical approach have had an influence on the perception and beliefs positively. The researcher however noticed a dearth of literature in India regarding cross-curricular pedagogical approach, especially with respect to children with developmental disabilities and their learning outcomes which indicates the 
importance of this research.

\section{Objectives Of the Study}

The objectives of the study are:

1. To study the level of awareness of general teachers and special educators regarding the term cross-curricular pedagogical approach.

2. To study the perspective of general teachers and special educators regarding the cross-curricular pedagogical approach for children with developmental disabilities with reference to their age and years of experience.

3. To study the general perspective of teachers regarding linking other subject disciplines in the interest of promoting learning for children with developmental disabilities.

\section{Hypothesis Of the Study}

Following is the hypothesis of the study:

There will be no significant association in the perspective of general teachers and special educators regarding the cross-curricular pedagogical approach for children with developmental disabilities with reference to age and years of experience.

\section{Research Methodology}

Survey method was employed in this research for the purpose of examining the awareness and perspective of teachers regarding cross-curricular pedagogical approach.

\section{Sample And Sampling Technique}

100 Teachers (50 General Teachers and 50 Special Educators) were selected as per the below given criteria of inclusion and exclusion using a purposive sampling technique.

\section{Inclusion Criteria:}

- Both Teachers - General Teachers and Special Educators

- Teachers working in Inclusive Schools in Delhi-NCR region 
287 Shaina Mary Paul and Naveen Singh

- Teachers teaching in Primary Level (Classes 1-5)

- Both Genders

\section{Exclusion Criteria:}

- Teachers working in Special Schools.

- Both Teachers - General Teachers and Special Educators working in schools outside the Delhi-NCR region.

- Teachers teaching in Pre-Primary \& Secondary and Higher Secondary Levels

\section{RESUlts OF THE STUdY}

The researcher obtained information from the respondents directly through a self-developed questionnaire. Data analysis was performed using descriptive and inferential statistics. To find out the associations in the variables selected, Pearson Chi-Square Test of Independence was employed using the SPSS software.

\section{Table 1}

Level of Awareness of General Teachers and Special Educators Regarding the term Cross-Curricular Pedagogical Approach.

\begin{tabular}{lcc}
\hline Teachers & Yes (\%) & No (\%) \\
\hline General Teachers & 56 & 44 \\
Special Educators & 80 & 20 \\
\hline
\end{tabular}

The data in Table 1 and Figure 1 reflects the level of awareness of General Teachers $(n=50)$ and Special Educators $(N=50)$ out of which $56 \%$ of general teachers and $80 \%$ of special educators are aware of the term cross-curricular pedagogical approach.

Data in Table 2 and Figure 2 reflects the percentage of General Teachers $(n=50)$ and Special Educators $(\mathrm{N}=50)$ who have attended workshop/training session on cross-curricular pedagogical approach out of which $22 \%$ of general teachers and $34 \%$ of special educators have attended workshops/training sessions on cross-curricular pedagogical approach. 
Cross- Curricular Pedagogical Approach | 288

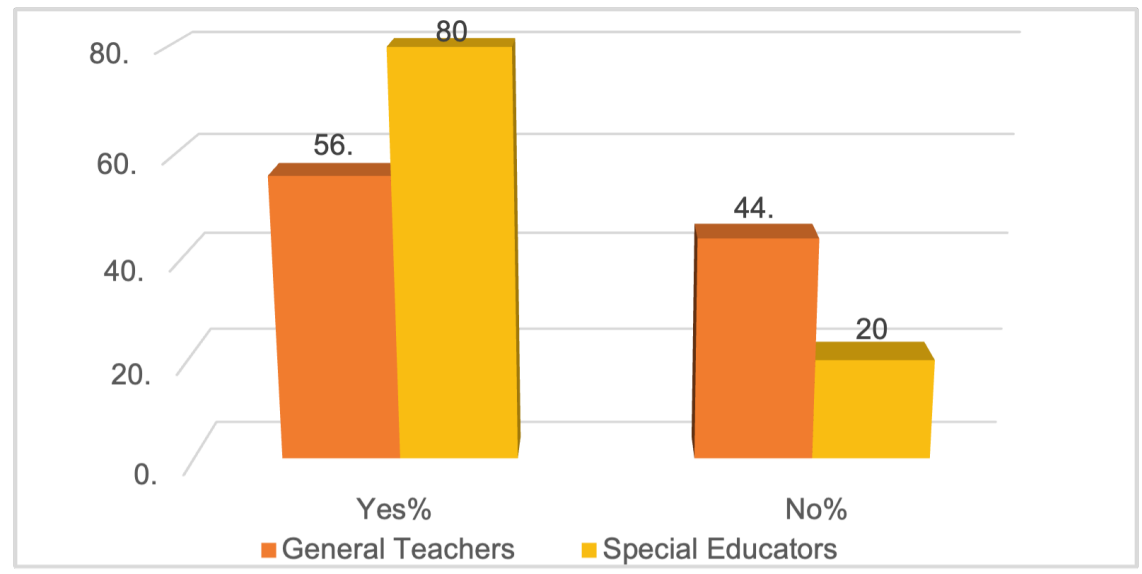

Figure 1. Level of Awareness of General Teachers and Special Educators Regarding the term Cross-Curricular Pedagogical Approach.

\section{Table 2}

Percentage of General Teachers and Special Educators who have Attended Workshops/Training sessions on Cross-Curricular Pedagogical Approach.

\begin{tabular}{lll}
\hline Teachers & Yes (\%) & No (\%) \\
\hline General Teachers & 22 & 78 \\
Special Educators & 34 & 66 \\
\hline
\end{tabular}

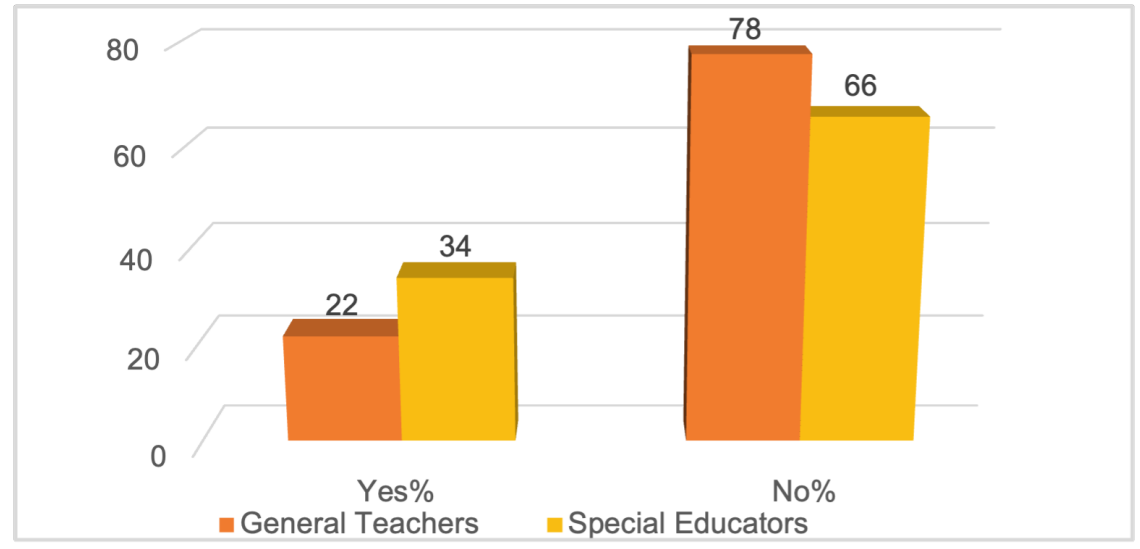

Figure 2. Percentage of General Teachers and Special Educators who have Attended Workshops/Training sessions on Cross-Curricular Pedagogical Approach. 
Table 3

Association of the Perspective of General Teachers $(\mathrm{N}=50)$ On Whether Linkages Can Be Made Between Varied Subject Disciplines for Teaching Children with Developmental Disabilities in Inclusive Classrooms with Reference to Age Groups.

\begin{tabular}{llcccc}
\hline S.No & Age Groups & N & No (\%) & Yes (\%) & $p$ \\
\hline 1 & $20-25$ & 10 & & 100 & \\
2 & $26-30$ & 13 & 7.7 & 92.3 & \\
3 & $31-35$ & 2 & 50 & 50 & 0.243 \\
4 & $36-40$ & 3 & 33.3 & 66.7 & \\
5 & $>40$ & 22 & 18.2 & 81.8 & \\
\hline
\end{tabular}

If the value of Pearson Chi-square is $<0.05$, then it is statistically significant .

According to the Pearson Chi-Square Test of Independence (Table 3), Value of Pearson Chi-Square, $p=0.243,(>0.05)$, is statistically not significant, stating that there is no significant association. Hence, the null hypothesis that states that there will be no significant association in the perspective of general teachers regarding the cross-curricular pedagogical approach for children with developmental disabilities with reference to age stands accepted.

\section{Table 4}

Association of the Perspective of General Teachers $(\mathrm{N}=50)$ On Whether Linkages Can Be Made Between Varied Subject Disciplines for Teaching Children with Developmental Disabilities in Inclusive Classrooms with Reference to Years of Experience.

\begin{tabular}{llcccc}
\hline S.No & Years of Experience & N & No (\%) & Yes (\%) & $p$ \\
\hline 1 & $0-5$ & 21 & 4.8 & 95.2 & \\
2 & $6-10$ & 5 & 0 & 100 & 0.066 \\
3 & $11-15$ & 4 & 50 & 50 & \\
4 & $>15$ & 20 & 20 & 80 & \\
\hline
\end{tabular}

If the value of Pearson Chi-square is $<0.05$, then it is statistically significant.

According to the Pearson Chi-Square Test of Independence (Table 4), Value of Pearson Chi-Square, $p=0.066,(>0.05)$ is statistically not significant. Hence, the null hypothesis that states that there will be no significant association in the perspective of general teachers regarding the cross-curricular pedagogical approach for children with developmental disabilities with reference to years 
of experience stands accepted.

Table 5

Association of the Perspective of Special Educators $(\mathrm{N}=50)$ On Whether Linkages Can Be Made Between Varied Subject Disciplines for Teaching Children with Developmental Disabilities in Inclusive Classrooms with Different Age Groups.

\begin{tabular}{llcccc}
\hline S.No & Age Groups & N & No $(\%)$ & Yes (\%) & $p$ \\
\hline 1 & $20-25$ & 19 & & 100 & \\
2 & $26-30$ & 10 & & 100 & \\
3 & $31-35$ & 8 & 12.5 & 87.5 & 0.253 \\
4 & $36-40$ & 2 & & 100 & \\
5 & $>40$ & 11 & & 100 & \\
\hline
\end{tabular}

If the value of Pearson Chi-square is $<0.05$, then it is statistically significant

According to the Pearson Chi-Square Test of Independence (Table 5), Value of Pearson Chi-Square, $p=0.253,(>0.05)$ is statistically not significant. Hence, the null hypothesis that states that there will be no significant association in the perspective of Special Educators regarding the cross-curricular pedagogical approach for children with developmental disabilities with reference to age stands accepted.

Table 6

Association of the Perspective of Special Educators $(\mathrm{N}=50)$ On Whether Linkages Can Be Made Between Varied Subject Disciplines for Teaching Children with Developmental Disabilities in Inclusive Classrooms with Years of Experience.

\begin{tabular}{llcccc}
\hline S.No & Years of Experience & N & No (\%) & $\begin{array}{l}\text { Yes } \\
\mathbf{( \% )}\end{array}$ & $p$ \\
\hline 1 & $0-5$ & 31 & & 100 & \\
2 & $6-10$ & 8 & 12.5 & 87.5 & 0.147 \\
3 & $11-15$ & 2 & & 100 & \\
4 & $>15$ & 9 & & 100 & \\
\hline
\end{tabular}

If the value of Pearson Chi-square is $<0.05$, then it is statistically significant

Data in Table 6 shows that the value of Pearson Chi-Square, $p=0.147$, $(>0.05)$ is statistically not significant. Hence, the null hypothesis that states that 
there will be no significant association in the perspective of special educators regarding the cross-curricular pedagogical approach for children with developmental disabilities with reference to years of experience stands accepted.

Approximately $29 \%$ teachers had the opinion of integrating co-curricular subjects like music, art, sports and drama with core subjects as an effective approach for promoting learning for children with developmental disabilities. Many combinations were suggested with art, such as art with science, english, math, or history. Other cross-curricular links that were suggested by the teachers were science and social studies, Language and science or social studies, music and math, or math and science. While approximately $7 \%$ teachers felt that almost all subject carries a scope to be cross-linked with each other and in any combinations. However, 51\% teachers didn't convey any clear responses regarding this.

It was found that $56 \%$ of general teachers and $80 \%$ of special educators are aware of the term cross-curricular pedagogical approach. And much to our surprise only $22 \%$ of general teachers and $34 \%$ of special educators have attended workshops/training sessions on 'cross-curricular pedagogical approach'. Majority of general teachers and special educators also expressed a positive perception towards forging linkages between subject disciplines for teaching children with developmental disabilities in inclusive classrooms. The findings of the present study also show that approximately $29 \%$ teachers expressed an interest in a curriculum structured with an infusion of various art forms such as music, creative movement, visual arts, and drama with core subjects.

\section{Conclusions OF THE Study}

Creative Education is not a mere subject in the curriculum but a general function of education. It should be promoted through a systemic strategy that addresses various components of education primarily including training and development of teachers. Hence, highlighting the importance towards enhancing critical engagement and the pedagogical knowledge regarding such innovative approaches in the teaching training programs. It is also only then we would come closer to the realisation of the objective stated in National Education Policy 2020 with respect to cross-curricular pedagogical approach in India. The research study also provides guidelines for future research studies to investigate the effectiveness of cross-curricular pedagogical approach especially with respect to children with developmental disabilities. 


\section{REFERENCES}

Barnes, J. (2015). An Introduction to Cross Curricular Learning. In P. Driscoll, A. Lambirth, \& J. Roden (Eds.), The Creative Primary Curriculum (2nd ed.). Sage Publication.

Greenwood, R. (2013). Subject-based and cross-curricular approaches within the revised primary curriculum in Northern Ireland: teachers' concerns and preferred approaches. Education, 41(4), 443-458. https:/ / doi.org/10.1080/03004279.2013.819618

Jacobs, H. H. (1989). The Growing Need for Interdisciplinary Curriculum Content. In H. H. Jacobs (Ed.), Interdisciplinary curriculum: Design and implementation. Alexandria, VA: Association for Supervision and Curriculum Development.

jan-erik Romar, Bjorkgren, M., Snellman, J., Ruostekoski, A., \& Juslenius, V. (2020). Preservice secondary subject teachers incorporating movement integration into classroom practice. Teaching and Teacher Education, 94, 103-119. https:// doi.org/10.1016/j.tate.2020.103119

Lynch, S. (2016). A Practitioner's Guide for Outstanding Cross-curricular Physical Education. Strategies, 29(3), 48-50. https:// doi.org/10.1080/08924562.2016.1160474

Murphy, P. (2008). Defining pedagogy. In K. Hall, P. Murphy, \& J. Soler (Eds.), Pedagogy and practice: culture and identities (p. 28-39). London: SAGE publications.

Palmer, J. (1991). Planning Wheels Turn Curriculum Around. Educational Leadership, 49(2), 57-60.

Thomson, P., Hall, C., \& Jones, K. (2012). Creativity and cross-curriculum strategies in England: Tales of doing, forgetting and not knowing. International Journal of Educational Research, 55, 6-15. https:// doi.org/10.1016/j.ijer.2012.06.003

Timmerman, V. (2017). Cross-curricular teaching: How does it work? . France Education International. Retrieved from france-education-international.fr/sites/default/files/atoms/files/ crosscut-cross-curricular-teaching-how-does-it-work-synthesis.pdf 